\title{
Evaluation of kinetic pseudo-order in the photocatalytic degra- dation of ofloxacin
}

\author{
Giora Rytwo ${ }^{1,2^{*}}$ and Arye Lev Zelkind ${ }^{1,2}$
}

1 Environmental Sciences \& Water Sciences Departments, Tel Hai College; rytwo@telhai.ac.il

2 Environmental Physical Chemistry Laboratory, MIGAL- Galilee Research Center

* Correspondence: rytwo@telhai.ac.il; Tel.: +972-4-7700516 (GR)

\begin{abstract}
Ofloxacin is an extensively used efficient antibiotic. However, since it is a refractory pollutant, it is found in water sources, requiring methods to remove it from the environment. Advanced Oxidation Processes (AOPs) offer efficient alternatives since it yields complete degradation not achieved in adsorption or membrane processes. Kinetics of degradation process require monitoring the "pseudo-order" of it to deliver evaluation of the proposed AOPs. Most studies assume ofloxacin degradation follows pseudo-first or -second order processes, whereas for full removal of refractory pollutants - lower pseudo-orders are required. This study presents a simple procedure to evaluate pseudo-orders of AOPs. Photolysis of $20 \mu \mathrm{M}$ ofloxacin follows pseudo-zero order, with half-life time $\left(\mathrm{t}_{1 / 2}\right)$ of $\sim 60 \mathrm{~min}$. Very low $\mathrm{TiO}_{2}$ concentration in heterogeneous catalysis $\left(0.2 \mathrm{mg} \mathrm{L}^{-1}\right)$ has no influence but increasing catalyst to $2.0 \mathrm{mg} \mathrm{L}^{-1}$ reduces $\mathrm{t}_{1 / 2}$ to $20 \mathrm{~min}$, increasing pseudo-order to 0.8 . Similar results are obtained with $2.0 \mathrm{mg} \mathrm{L}^{-1} \mathrm{H}_{2} \mathrm{O}_{2}$ homogenous catalysis. Combining $\mathrm{H}_{2} \mathrm{O}_{2}$ with $\mathrm{TiO}_{2}$ reduces $\mathrm{t}_{1 / 2}$, but pseudo-order increases further (1.2). The conclusions are (1) ofloxacin can be effectively degraded by both heterogenous and homogenous photocatalysis, (2) combined photocatalysis yields higher pseudo-order, being less prone to achieve full removal, (3) analysis of specific pseudo-order in AOPs of refractory pollutants helps to further elucidate the efficiency of the process presented.
\end{abstract}

Keywords: ofloxacin, rate law, pseudo-order, half-life time, homogeneous catalysis, heterogeneous catalysis, photodegradation

\section{Introduction}

Ofloxacin (OFL) is a third-generation fluoroquinolone antibiotic, that has been extensively used to prevent or treat human and animal bacterial infection due to its broadspectrum antibacterial properties [1]. Accordingly, it was found at significant concentrations in surface water and wastewater treatment plants (up to $1.8 \mu \mathrm{g} \mathrm{L}^{-1}$ ), and even 20 folds larger concentrations in hospital effluents [2]. It is considered refractory to biodegradation [3], thus it requires specific and effectives methods to remove it from the environment. Advanced Oxidation Processes (AOPs) may offer an effective alternative to remove refractory pollutants in water [4]. AOPs in general and photocatalysis in particular are widely studied and reviewed[5] due to advantages as high efficiency, low cost, practicality, and environmental friendliness. An important superiority over other methods as adsorption, membrane separation or flocculation is that those cannot completely decompose pollutants and they only separate them from the water, whereas AOPs- if performed effectively- yields complete decomposition of the organic pollutants[6].

Several studies on AOP processes for the removal of refractory fluoroquinolone antibiotics in general and OFL in particular were reported in the last years. This includes direct photochemistry (photolysis)[7] and the influence of natural colloids on it[1], photocatalytic degradation combining $\mathrm{UV} / \mathrm{TiO}_{2}$ and $\mathrm{UV} / \mathrm{TiO}_{2} / \mathrm{H}_{2} \mathrm{O}_{2}$ [2], use of photo-assisted microbial fuel cells with LiNbO3/CF photocatalytic cathodes[8], UV combined with hydrogen peroxide or persulfate[9,10], heterogenous persulfate catalysis with Mn doped 
$\mathrm{CuO}$ particles[11] or $\mathrm{MnCeOx}$ composites[4]. Fenton based processes combining $\mathrm{MnFe}_{2} \mathrm{O}_{4}$ magnetic particles[3], ozonation and peroxone processes[1] were found also successful.

Such vast amounts of research during the last years is ascribed to the environmental importance of removing low concentration of such refractory antibiotics from water. In the process of describing the degradation achieved by such AOPs, usually "rate laws" are developed. Rate laws describe the relationship between the concentrations of reactants and the rate of a specific reaction. In most cases such laws helps to elucidate the full kinetic process, and in some cases- even the mechanism[12]. A full rate law should include the concentrations of all the reactants in a process. For example, Batakliev et al. [13] present a series of proposed mechanisms for the decomposition of ozone, considering all possible participants including light, free electrons, molecular and atomic oxygen, and even "third particles" (additional chemicals or compounds. Such full mechanism rate laws are usually complicated, and include several experimentally determined rate coefficients, and the concentrations of all participants influencing at different orders, whereas the "kinetic order" of a participant is an experimentally determined parameter, defined as "the power dependence of the rate on the concentration of each reactant" [14].

When the focus is mostly on one of the components of the process, as in the catalyzed degradation of refractory pollutants as ofloxacin, and all other participants in the reaction are in non-limited amounts, and/or kept constant, a simpler rate law might be defined as[15]:

$$
v=\frac{d[A]}{d t}=-k_{a p p}[\mathrm{~A}]^{n_{a p p}}
$$

where $v$ is the reaction rate, $k_{a p p}$ is the apparent rate coefficient, $A$ is the concentration of the pollutant in case, and napp is the apparent or "pseudo" reaction order[16,17]. The term "apparent" or "pseudo" is used to acknowledge the fact that all other influencing parameters (catalyst/degradation agent, temperature, light, etc.) were kept constant [18]. In most cases the to allow comparison between parameters in different reaction mechanisms, the dimensionless "relative concentration at time $t^{\prime}$ is defined as $[A]_{(t)}=C_{t} / C_{0}$ (the ratio of actual to initial concentration).; thus $\mathrm{A}_{0}=1$. This is convenient since it yields apparent kinetic coefficients that always have dimensions of time ${ }^{-1}$, regardless of the order of the process [19].

Equation (1) can be easily integrated if $n_{\text {app }} \neq 1$, and the concentration at time $t$ can be calculated if the kinetic rate coefficient $k_{a p p}$ and the pseudo-order $n_{\text {app }}$ are known, using

$$
[A]_{(t)}=\left(\frac{1}{\frac{1}{\left[A_{0}\right]^{n_{a p p}-1}+\left(n_{a p p^{-1}}\right) k_{a p p} t}}\right)^{\frac{1}{n_{a p p^{-1}}}}
$$

And for the specific case of pseudo-first order, were $n_{a p p}=1$, the integration yields:

$$
\frac{d[A]}{A}=-k_{a p p} d t \rightarrow[A]_{(t)}=[A]_{0} e^{-k_{a p p} t}
$$

Since it is impossible to numerically compare kinetic rate coefficients for different pseudo-order processes, it is helpful to define the time taken for the concentration of a reactant to fall to half its initial value as the "half-life time" ( $\left.\mathrm{t}_{1 / 2}\right)[17]$. Half-lives times can be evaluated by solving mathematically Eq. $(2)$ and (3) to the case were $[A](t)=0.5$, yielding for $n_{\text {app }} \neq 1$

$$
t_{1 / 2}=\frac{2^{n_{a p p}-1}-1}{\left(n_{a p p}-1\right) k_{a p p}\left[A_{0}\right]^{n_{a p p}-1}}
$$


And for $n_{a p p}=1$ :

$t_{1 / 2}, n=1=\frac{\ln (2)}{k_{a p p}}$

It is interesting to note that for all orders except $n_{a p p}=1$, half-life times strongly depends on the initial concentration. Thus, when interested in the degradation of a refractory pollutant, the rate law is crucial for the determination of the efficiency of the process. In this sense, the specific pseudo-order of the pollutant is of course important.

In most studies presenting degradation of OFL, the order is found empirically by fitting the relative concentration $\left(\mathrm{C}_{t} / \mathrm{C}_{0}\right)$ at several times of measurement to a pseudo first or even pseudo second order process $[1,4,6,7,10,11,20]$. In all those cases the fit is based on 5-10 experimental data points. However, it should be emphasized that high pseudo-orders yield higher degradation rates $\left(\frac{d[A]}{d t}\right)$ and lower half-life times at large concentrations, but at very low pollutant concentrations - lower orders yield better performance. For example, consider different suggested degradation processes yielding the same half-life times at an initial pollutant concentration of $1 \mu \mathrm{M}$ : If the process is pseudo-first order, halflife time will remain constant, independent from the initial concentration (see Eq.3). However, this is will not be the case for a "pseudo second order" or a "pseudo-zero order" (see Eq.2). If the initial concentration increases by ten folds to $10 \mu \mathrm{M}$, the half-life time of the pseudo second order will indeed be beneficiated and decrease by 10 -fold. But if the initial concentration is very low (for example $0.01 \mu \mathrm{M}$ ) the half-life time will increase 100 times, yielding almost no efficient degradation. On the other hand, for the "pseudo zero order" process, reaction rate will remain unchanged, and half-life times at the low concentration will be reduced 100 fold- thus at lower concentration such low order processes should be preferred[21].

This study focuses on the photocatalytic degradation of OFL by combining UV/ $\mathrm{TiO}_{2}$, $\mathrm{UV} / \mathrm{H}_{2} \mathrm{O}_{2}$ and $\mathrm{UV} / \mathrm{TiO}_{2} / \mathrm{H}_{2} \mathrm{O}_{2}$, and in this sense it is similar to previous studies [2], although our work was performed at considerably lower catalysts concentration. The studyt also presents a procedure that allows to better evaluate the pseudo-order of degradation processes in general, and by that- might allow relatively objective comparison of the efficiency of refractory pollutants removal using AOP processes.

\section{Results and Discussion}

\subsection{Optimization procedure}

The optimization procedure to find the pseudo-order that exhibits the best fit to each of the treatments was performed as described in Rytwo et al. [21]: From the large amount of data (120-250 data points) in each experiment, a "bootstrap" [22,23] procedure was performed by choosing 5 sets of 20 values for each experiment. Values of kinetic rate coefficient ( $\mathrm{k}_{\mathrm{app}}$ ) and pseudo-order ( $\mathrm{n}_{\mathrm{app}}$ ) were found by evaluating [A](t) using Eq. (2) and finding to each treatment the best possible parameters using the "Solver" algorithm in Excel ${ }^{\circledR}$ software, to minimize the root mean square error (RMSE) between all measured and calculated $[\mathrm{A}]_{(\mathrm{t})}$ values in the treatment. Half-life times were evaluated with Eq.(3). Such procedure yielded the pseudo-order that yields the best fit, and its relevant half-life time. As a comparison a similar procedure was perform fixing pseudo-orders to $0,0.5,1$ and 2, and finding the optimal kapp (and accordingly, $\mathrm{t}_{1 / 2}$ ) for each fixed pseudo-order. As can be understood, RMSE for those evaluations- based only on optimization of kapp and without optimizing napp- were considerably higher than in the cases when optimizations were evaluated based on both kapp and napp. All calculation results are concentrated in Table 1. It should be noted that since the ranges of values for $\mathrm{Ct} / \mathrm{C}_{0}$ are $0-1$, RMSE values for the best fit are indeed very low $(<0.0001)$, as can be observed also from the fact that measured and best lines in Figs. 1-5 are in complete match. 


\subsubsection{Photolysis}

The photodegradation of OFL at an initial concentration of $20 \mu \mathrm{M}\left(7.23 \mathrm{mg} \mathrm{L}^{-1}\right)$ with no catalysts (photolysis experiment) is shown in Figure 1. Red squares show the experimental measured results, whereas lines are evaluated as described in section 2.1. Note that dashed line describing the best fit is directly above measured results, making it very difficult to distinguish between them.

Table 1. Pseudo-orders, half-life times and root mean square errors for all AOP treatments of $20 \mu \mathrm{M}$ of ofloxacin. The first row in each treatment (in italics) represents the best fit, with errors calculated by bootstrap procedure

\begin{tabular}{|c|c|c|c|}
\hline Treatment & $\begin{array}{l}\text { Pseudo-order } \\
\qquad n_{a p p}\end{array}$ & $\begin{array}{c}\text { Half life } \\
\mathbf{t}_{1 / 2} \\
(\mathrm{~min})\end{array}$ & $\begin{array}{c}\text { RMSE } \\
\left(\times 10^{3}\right)\end{array}$ \\
\hline \multirow{5}{*}{ OFL/UV (photolysis) } & $0.283 \pm 9.63 \%$ & $59.2 \pm 0.30 \%$ & $0.0071 \pm 15.2 \%$ \\
\hline & 0 & 59.3 & 0.102 \\
\hline & 0.5 & 59.4 & 0.054 \\
\hline & 1 & 60.6 & 0.445 \\
\hline & 2 & 65.8 & 1.907 \\
\hline \multirow{5}{*}{$\mathrm{OFL} \mathrm{TiO}_{2} 0.2 \mathrm{mg} \mathrm{L}-1 / \mathrm{UV}$} & $0.261 \pm 14.2 \%$ & $57.1 \pm 0.31 \%$ & $0.0067 \pm 28.7 \%$ \\
\hline & 0 & 56.9 & 0.060 \\
\hline & 0.5 & 57.8 & 0.052 \\
\hline & 1 & 59.5 & 0.334 \\
\hline & 2 & 65.5 & 1.411 \\
\hline \multirow{5}{*}{$\mathrm{OFL} / \mathrm{H}_{2} \mathrm{O}_{2} 2 \mathrm{mg} \mathrm{L}^{-1} / \mathrm{UV}$} & $0.701 \pm 6.98 \%$ & $20.7 \pm 0.88 \%$ & $0.0786 \pm 44.9 \%$ \\
\hline & 0 & 23.3 & 2.643 \\
\hline & 0.5 & 21.3 & 0.289 \\
\hline & 1 & 20.1 & 0.376 \\
\hline & 2 & 19.1 & 3.673 \\
\hline \multirow{5}{*}{$\mathrm{OFL} / \mathrm{TiO}_{2} 2 \mathrm{mg} \mathrm{L}^{-1} / \mathrm{UV}$} & $0.830 \pm 3.42 \%$ & $19.8 \pm 1.38 \%$ & $0.0618 \pm 29.7 \%$ \\
\hline & 0 & 30.0 & 13.630 \\
\hline & 0.5 & 22.3 & 1.189 \\
\hline & 1 & 18.8 & 0.345 \\
\hline & 2 & 14.7 & 7.701 \\
\hline \multirow{5}{*}{$\begin{array}{c}\mathrm{OFL} / \mathrm{H}_{2} \mathrm{O}_{2} 2 \mathrm{mg} \mathrm{L}^{-1} / \mathrm{TiO}_{2} \\
2 \mathrm{mg} \mathrm{L}^{-1} / \mathrm{UV}\end{array}$} & $1.205 \pm 1.17 \%$ & $16.3 \pm 0.71 \%$ & $0.0082 \pm 52.7 \%$ \\
\hline & 0 & 29.0 & 23.22 \\
\hline & 0.5 & 20.6 & 4.756 \\
\hline & 1 & 17.4 & 0.324 \\
\hline & 2 & 13.5 & 2.946 \\
\hline
\end{tabular}

As shown in Table 1 , the best fit is at a pseudo-order of $\sim 0.3$, thus pseudo-orders of 0 and 0.5 exhibit also a quit close fit, with relatively low RMSE values. Half-life time as evaluated from kinetic coefficient and pseudo-order (Eq. (3)) yields approximately 59.2 min, and the sensitivity of this parameter to the pseudo-order is not very significant for all the range of pseudo-orders 0 - 1 . It can be seen that high pseudo-orders $(1,2)$ deliver underestimate at high relative concentrations and overestimate the remaining concentrations at low relative concentrations.

2.2.2. Heterogenous photocatalysis with low concentration of $\mathrm{TiO}_{2}$ 


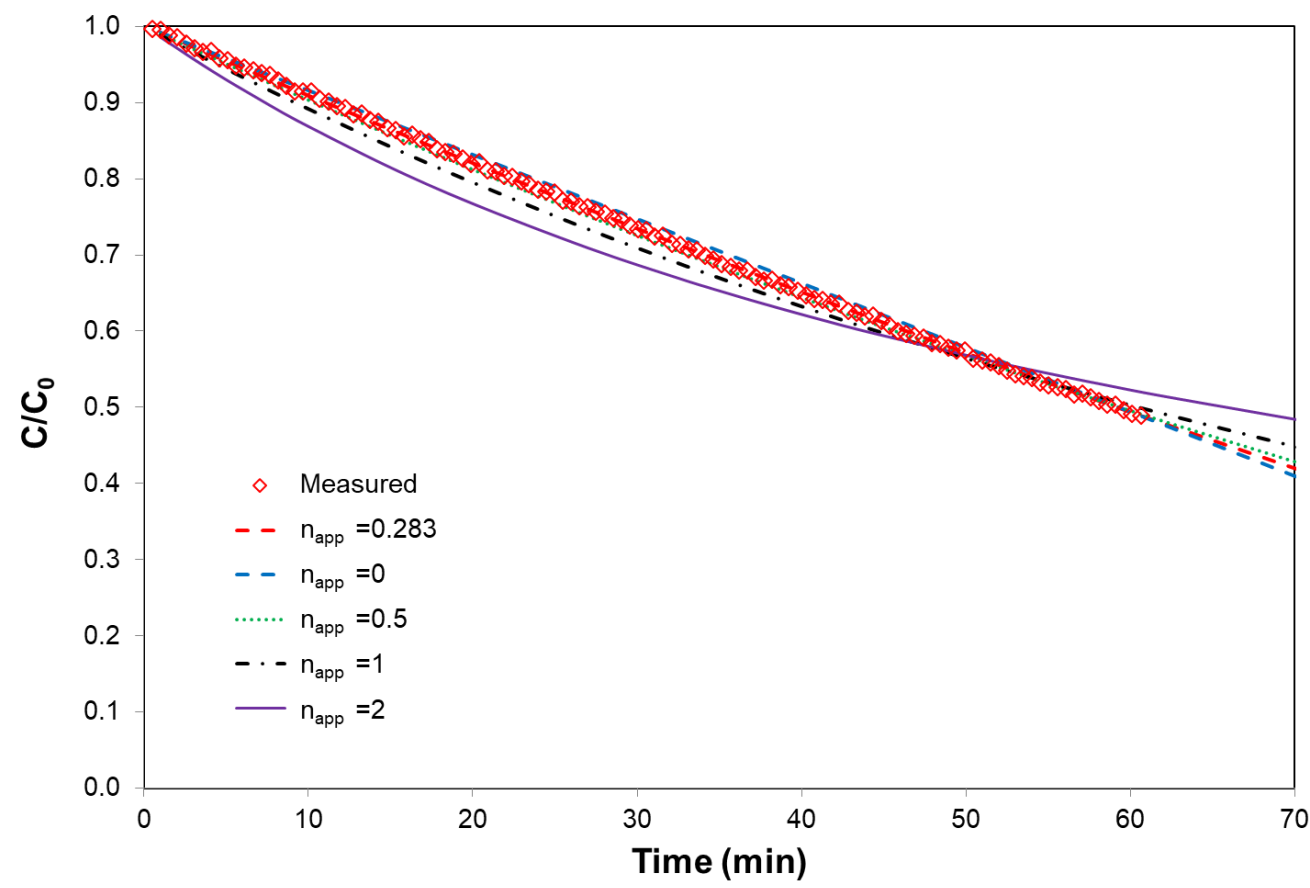

Figure 1. Photolysis of $20 \mu \mathrm{M}$ ofloxacin. Red squares represent measured values, whereas lines represent different calculated amounts using Eq.2-3 and optimized kinetic coefficient parameters (see Table 1).

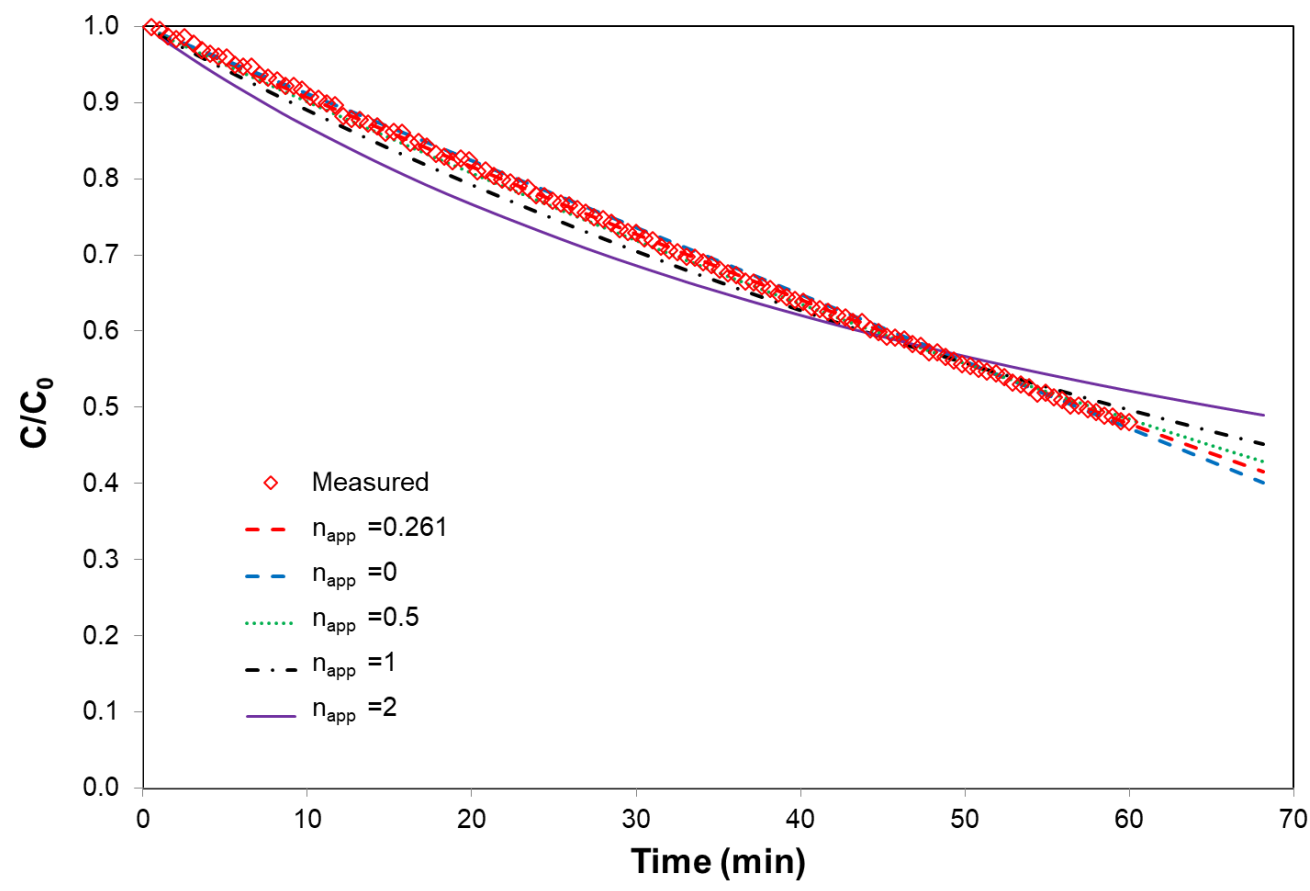

Figure 2. Photocatalytic degradation of $20 \mu \mathrm{M}$ ofloxacin in the presence of $0.2 \mathrm{mg} \mathrm{L}^{-1} \mathrm{TiO}_{2}$. Red squares represent measured values, whereas lines represent different calculated amounts using Eq.2-3 and optimized kinetic coefficient parameters (see Table 1).

$\mathrm{TiO}_{2}$ is the most popular photocatalyst for the photodegradation of organic refractory pollutants[20]. In most heterogenous photocatalysis based AOP processes, concentration of the catalyst is from tens to thousands $\mathrm{mg} \mathrm{L}^{-1}[24]$. Figure 2 shows photodegradation of a $20 \mu \mathrm{M}$ OFL solution, under UV irradiation, with the addition of high quality catalytic $\mathrm{TiO}_{2}$ as a heterogeneous catalyst, at very low concentration $\left(0.2 \mathrm{mg} \mathrm{L}^{-1}\right)$. It should be 
mentioned that such low concentration has been found to be relatively effective in the photocatalysis of bisphenol-S[21]. However, in this case such catalysts concentration does not exhibits any improvement when compared with photolysis without catalysts, and half-life times and pseudo-orders are almost the same for both treatments.

\subsubsection{Homogenous photocatalysis with $\mathrm{H}_{2} \mathrm{O}_{2}$}

Figure 3 shows photodegradation of a $20 \mu \mathrm{M}$ OFL solution, under UV irradiation, with the addition of $2 \mathrm{mg} \mathrm{L}^{-1}=58.8 \mu \mathrm{M} \mathrm{H}_{2} \mathrm{O}_{2}$ as homogenous catalyst. It should be emphasized that this is a very low concentration compared with the added in most previous studies[1-3,11,25]. However, in another recent study on photodegradation of BPS[21], such $\mathrm{H}_{2} \mathrm{O}_{2}$ concentration lowered $\mathrm{t}_{1 / 2}$ to about half of the photolysis value. In this case, the effect is even more impressive, and $\mathrm{t}_{1 / 2}$ is lowered from almost $1 \mathrm{~h}$ to $\sim 21 \mathrm{~min}$. On the other hand, pseudo-order increases to about 0.7 . Lower pseudo-orders $(0,0.5)$ underestimate the remaining concentration at large irradiation times (and low remaining relative concentrations), whereas a high pseudo-order (2) overestimates it.

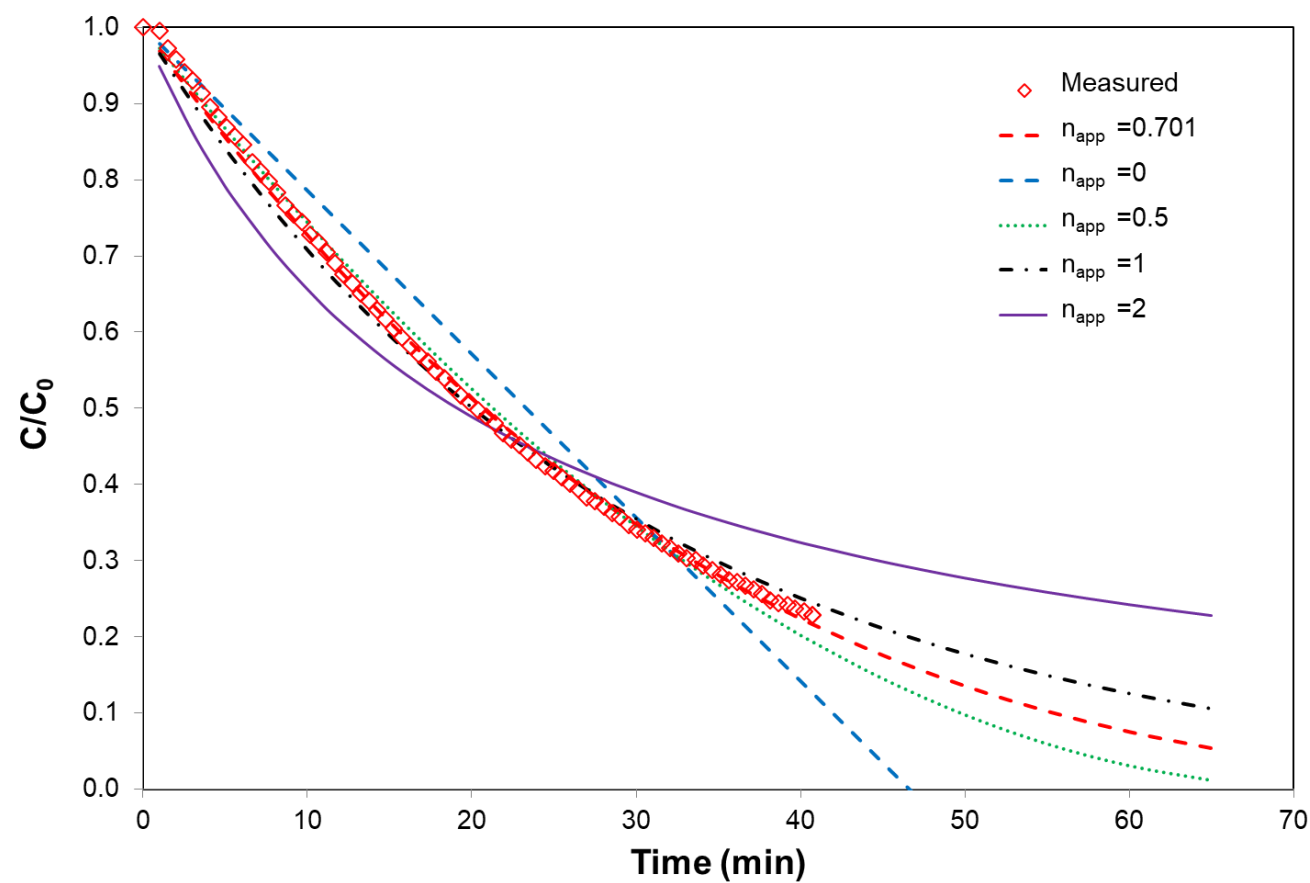

Figure 3. Photocatalytic degradation of $20 \mu \mathrm{M}$ ofloxacin in the presence of $2 \mathrm{mg} \mathrm{L}^{-1} \mathrm{H}_{2} \mathrm{O}_{2}$. Red squares represent measured values, whereas lines represent different calculated amounts using Eq.2-3 and optimized kinetic coefficient parameters (see Table 1).

\subsubsection{Heterogenous photocatalysis with high concentration of $\mathrm{TiO}_{2}$}

Considering (as mentioned in 2.2.2) that in most cases the usually used concentration of heterogeneous catalysts is relatively high, we tested degradation of $20 \mu \mathrm{M}$ OFL solution, under UV irradiation, with the addition of $2 \mathrm{mg} \mathrm{L}^{-1}$ high quality catalytic $\mathrm{TiO}_{2}$, and results are shown in Figure 4 . As can be seen from Table 1, $t_{1 / 2}$ is similar to the one obtained with $2 \mathrm{mg} \mathrm{L}^{-1} \mathrm{H}_{2} \mathrm{O}_{2}$, but the pseudo-order is slightly higher (0.83 instead of 0.70$)$. It is interesting to compare the results with the previous experiment reported in 2.2.2, with one order of magnitude lower amount of $\mathrm{TiO}_{2}$ : at the low concentration no effect at all was observed, and results were almost identical to those obtained with no catalyst at all. Not in all cases higher amount of catalysts lead to more effective process: In the degradation 
of BPS lowering the concentration of $\mathrm{TiO}_{2}$ indeed reduced the efficacy, but in clay based catalysts it improved considerably the efficiency of the process by lowering both $t_{1 / 2}$ and napp[21], presumably due to reduced light dispersion by the colloids in suspension[26].

It should be mentioned that such clay-based catalysts where also preliminary tested for the photodegradation of OFL but were found completely ineffective (results not shown). Thus- photodegradation processes, as any other water treatment method, are very specific, and an efficient catalyst for one pollutant might be completely ineffective for other.

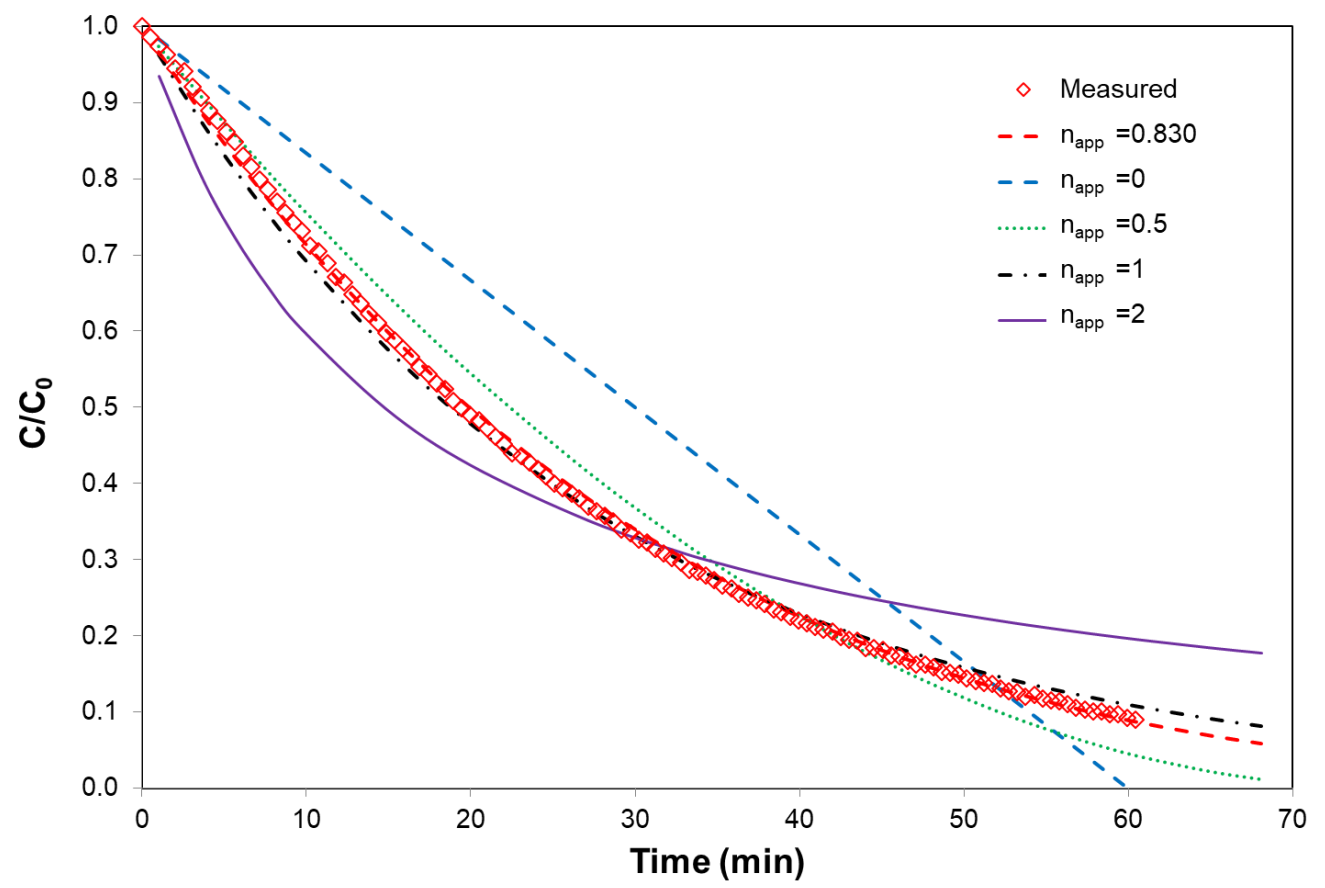

Figure 4. Photocatalytic degradation of $20 \mu \mathrm{M}$ ofloxacin in the presence of $2 \mathrm{mg} \mathrm{L}^{-1} \mathrm{TiO}_{2}$. Red squares represent measured values, whereas lines represent different calculated amounts using Eq.2-3 and optimized kinetic coefficient parameters (see Table 1).

\subsubsection{Combined heterogeneous/homogenous photocatalysis with $\mathrm{TiO}_{2}$ and $\mathrm{H}_{2} \mathrm{O}_{2}$}

Figure 5 shows photodegradation of a $20 \mu \mathrm{M}$ OFL solution, under UV irradiation, with the addition of $2 \mathrm{mg} \mathrm{L}^{-1}$ each- $\mathrm{H}_{2} \mathrm{O}_{2}$ and $\mathrm{TiO}_{2}$. It is interesting to notice that combination of both catalysts changes the process and yields a considerably higher value of pseudo-order ( 1.2 instead of 0.7-0.8). A decrease in the half-life time is observed (from $\sim 20$ to $16 \mathrm{~min}$ ), but a detailed observation of the results leads to the conclusion that if the purpose in the end is full removal of OFL, the combination of $\mathrm{H}_{2} \mathrm{O}_{2}$ and $\mathrm{TiO}_{2}$ is as the matter of fact less effective than when the catalysts are added separately. For example, if we compare Figs. 3, 4 and 5 , we can see that at $\mathrm{t} \approx 65 \mathrm{~min}$ the measured concentration in the combined $\mathrm{H}_{2} \mathrm{O}_{2}$ and $\mathrm{TiO}_{2}$ process is approximately $11 \%$ of the initial concentration, whereas in Fig.4 when there is only $\mathrm{TiO}_{2}$, remaining OFL is only about $7.5 \%$, and with $\mathrm{H}_{2} \mathrm{O}_{2}$ alone- (Fig.3) only $5.4 \%$. This happens even though $\mathrm{t}_{1 / 2}$ for the combined process is 16.3 min compared to 19.8 or 20.7 min for $\mathrm{TiO}_{2}$ or $\mathrm{H}_{2} \mathrm{O}_{2}$ alone, respectively. This simple example emphasizes that the conception at first sight that higher pseudo-orders should be preferred- is erroneous, and for effective complete removal the benefits of lower pseudo-orders are significant. 


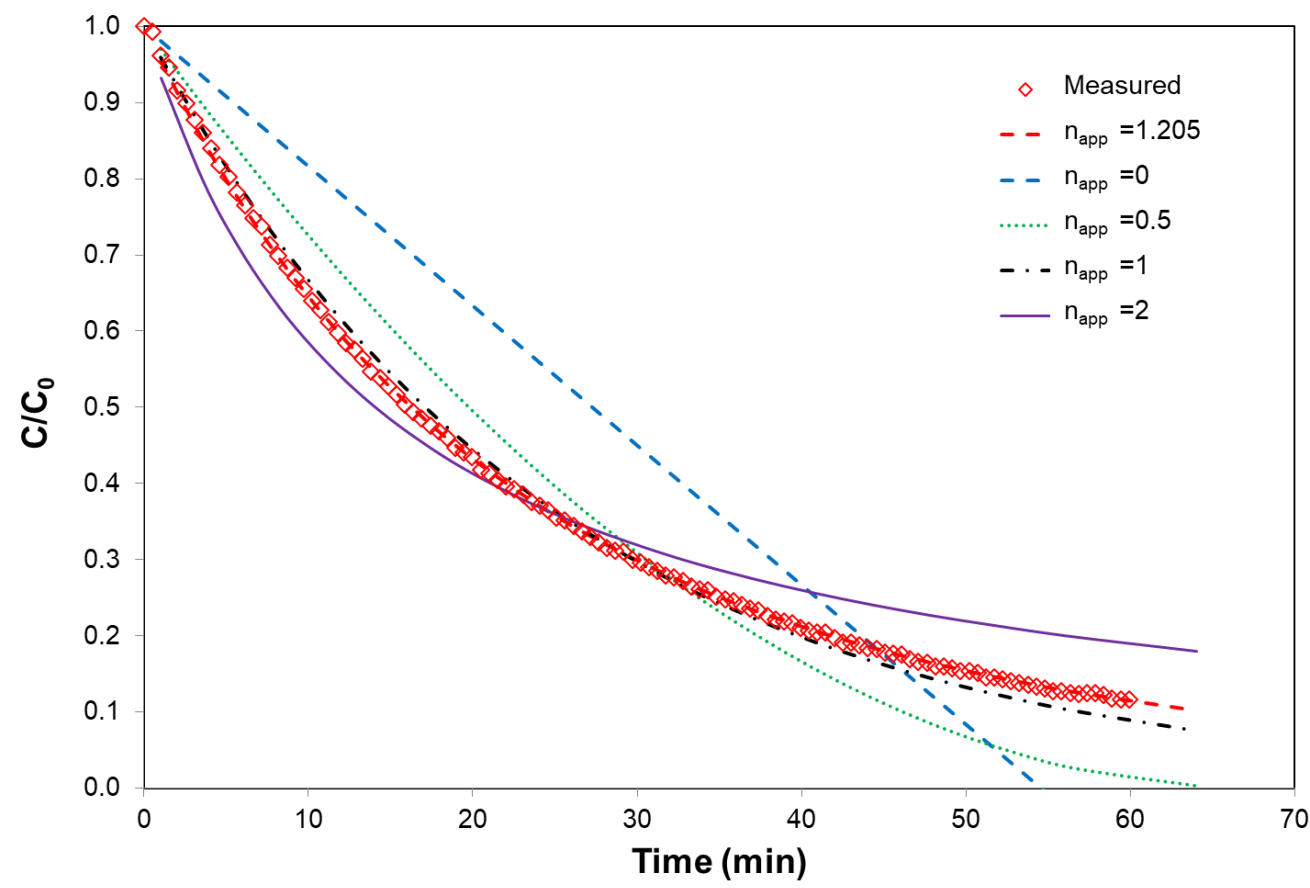

Figure 5. Photocatalytic degradation of $20 \mu \mathrm{M}$ ofloxacin in the presence of $2 \mathrm{mg} \mathrm{L}^{-1} \mathrm{H}_{2} \mathrm{O}_{2}$ and $\mathrm{TiO}_{2}$. Red squares represent measured values, whereas lines represent different calculated amounts using Eq.2-3 and optimized kinetic coefficient parameters (see Table 1).

\section{Materials and Methods}

\subsection{Optimization procedure}

Ofloxacin $\left(\mathrm{C}_{18} \mathrm{H}_{2} \mathrm{FN}_{3} \mathrm{O}_{4}\right)$, catalyst-grade industrial $\mathrm{TiO}_{2}\left(\mathrm{Hombikat}^{\circledR}\right)$ and a 30\% $(9.79$ M) concentrated $\mathrm{H}_{2} \mathrm{O}_{2}$ solution were obtained from Merck/ Sigma-Aldrich (Merck KGaA, Darmstadt, Germany). All materials were used without further treatment. All the experiments were performed at ambient conditions $\left(23 \pm 1^{\circ} \mathrm{C}\right)$.

\subsection{Methods}

The degradation of ofloxacin in all experiments was measured in batch experiments in a 100-mL UV-C-transparent quartz glass (refractive Index $n=1.5048$ ), 5.3 -cm diameter beaker placed in a Rayonet RMR-600 mini photochemical chamber reactor (Southern New England Ultraviolet Company, Branford, CT, USA), as described in previous studies[15,21,27]. The photoreactor was equipped with eight RMR 2537A lamps $(254 \mathrm{~nm}$ wavelength), each lamp emitting an average irradiance flux of $19 \mathrm{~W} \mathrm{~m}^{-2}$ at $254 \mathrm{~nm}$, equivalent to an overall intensity of $152 \mathrm{~W} \mathrm{~m}^{-2}$, as measured in the center of the chamber using a Black Comet SR spectrometer with an F400 UV-VIS-SR-calibrated fiber optic probe equipped with a CR2 cosine light receptor (StellarNet Inc., Tampa, Florida, USA). The same spectrometer was used to measure the spectrum of the solutions during experiments using a $20 \mathrm{~mm}$ pathlength DP400 dip probe cuvette placed inside the beaker. The solutions were constantly mixed with an external stirrer (VELP Scientifica, Usmate Velate, Italy) rotating at $100 \mathrm{rpm}$. Spectra were measured using the SpectraWiz software (StellarNet Inc., Tampa, Florida, USA) every 10-20 s for 50-70 min. Data was transformed to comma separated values (CSV) files, and absorption at the maximum absorption band of OFL (288 nm, $\left.\varepsilon_{288}=24240 \mathrm{M}^{-1} \mathrm{~cm}^{-1}\right)$ was downloaded after subtracting a baseline value at $450 \mathrm{~nm}$. To allow comparisons between parameters in different reaction mechanisms, the "relative dimensionless concentration at time $\mathrm{t}^{\text {" }}[\mathrm{A}]_{(\mathrm{t})}$ was evaluated [28] as $\mathrm{Ct} / \mathrm{C0}=$ $\mathrm{OD}_{\mathrm{t}} / \mathrm{OD}_{0}$ (the ratio of actual to initial concentration, or actual to initial light absorbance); thus $A_{0}=1$. Such procedure led to $>120-250$ data points for each experiment. Analysis of 
the data was performed as described in subsection 2.1. The experiments performed were as follows:

1. Photolysis (UV lamps, no catalysts) of a solution of $20 \mathrm{mM}$ OFL

2. Heterogeneous photocatalysis of a solution of $20 \mathrm{mM}$ OFL with $0.2 \mathrm{mg} \mathrm{L}^{-1}$ $\mathrm{TiO}_{2}$

3. Homogenous photocatalysis of a solution of $20 \mathrm{mM} \mathrm{OFL}$ with $2 \mathrm{mg} \mathrm{L}^{-1} \mathrm{H}_{2} \mathrm{O}_{2}$

4. Heterogeneous photocatalysis of a solution of $20 \mathrm{mM}$ OFL with $2 \mathrm{mg} \mathrm{L}^{-1} \mathrm{TiO}_{2}$

5. Combined hetero-homogeneous photocatalysis of a solution of $20 \mathrm{mM} \mathrm{OFL}$ with $2 \mathrm{mg} \mathrm{L}^{-1} \mathrm{TiO}_{2}$ and $2 \mathrm{mg} \mathrm{L}^{-1} \mathrm{H}_{2} \mathrm{O}_{2}$

\section{Summary and Conclusions}

- This study aims to present photocatalyzed degradation of the refractory antibiotic ofloxacin while emphasizing the importance of determining the specific pseudo-order of a process in the advanced oxidation photocatalysis of refractory pollutants.

- $\quad$ OFL can be photo catalytically degraded in minutes, depending on the pollutant concentration and the specific process chosen (e.g., type of catalyst and its concentration, type of light and its intensity, etc.). Of course that other compounds in solution may interfere and delay or in some cases even accelerate the degradation[15].

- The general assumption in most reported studies that AOPs are pseudo-first or pseudo-second order process, should be further examined. In this study, for example, all processes were neither pseudo-first nor -second order. Furthermore, it should be considered that at low concentrations a low pseudo-order can achieve completely removal, whereas a high pseudo-order process will lower pollutants concentration faster at the beginning but leave remains of pollutant in the treated water.

- Anachronistic linearizations performed in the past to determine the kinetic coefficients, are no longer required, and might be avoided even by using relatively simple and available worksheet software packages, as presented in this study- or using relatively simple computer codes. A simple worksheet for the evaluation of pseudoorders and half-life times when concentrations at different times along the degradation process are known was added to this manuscript and is available as "supplementary material".

Supplementary Materials: The following are available online at www.mdpi.com/xxx/s1, Worksheet W1: An example of kinetic parameters determination using "Solver" by Excel ${ }^{\circledR}$

Author Contributions: Conceptualization, G.R; methodology, G.R and A.L.Z.; software, A.L.Z..; validation, G.R and A.L.Z.; formal analysis, G.R.; investigation, G.R and A.L.Z.; resources, G.R and A.L.Z.; data curation, G.R and A.L.Z.; writing-original draft preparation, G.R.; writing-review and editing, G.R and A.L.Z.; visualization, G.R.; supervision, G.R.; project administration, G.R.; funding acquisition, G.R. All authors have read and agreed to the published version of the manuscript.

Funding: This research was partially funded by CSO-MOH (Israel), in the frame of the collaborative international consortium (REWA) financed under the 2020 AquaticPollutants Joint call of the AquaticPollutants ERA-NET Cofund (GA № 869178).

Data Availability Statement: All raw data can be available from the authors.

Acknowledgments: The authors would like to thank the European Commission and AKA (Finland), CSO-MOH (Israel), IFD (Denmark) and WRC (South Africa) for funding in the frame of the collaborative international consortium (REWA) financed under the 2020 AquaticPollutants Joint call of the AquaticPollutants ERA-NET Cofund (GA № 869178). This ERA-NET is an integral part of the activities developed by the Water, Oceans and AMR JPIs. The authors are also thankful to Shem Levi, Yuval Shahar and Barak Chen for their help in performing part of the experiments.

Conflicts of Interest: The authors declare no conflict of interest. 


\section{References}

1. Cheng, D.; Liu, H.; E, Y.; Liu, F.; Lin, H.; Liu, X. Effects of natural colloidal particles derived from a shallow lake on the photodegradation of ofloxacin and ciprofloxacin. Sci. Total Environ. 2021, 773, 145102.

2. Peres, M.S.; Maniero, M.G.; Guimarães, J.R. Photocatalytic degradation of ofloxacin and evaluation of the residual antimicrobial activity. Photochem. Photobiol. Sci. 2015, 14, 556-562.

3. Qin, H.; Yang, Y.; Shi, W.; She, Y. Heterogeneous Fenton degradation of ofloxacin catalyzed by magnetic nanostructured MnFe2O4 with different morphologies. Environ. Sci. Pollut. Res. 2021, 28, 26558-26570.

4. Niu, L.; Xian, G.; Long, Z.; Zhang, G.; Zhu, J.; Li, J. MnCeOX with high efficiency and stability for activating persulfate to degrade AO7 and ofloxacin. Ecotoxicol. Environ. Saf. 2020, 191, 110228.

5. Yang, X.; Chen, Z.; Zhao, W.; Liu, C.; Qian, X.; Zhang, M.; Wei, G.; Khan, E.; Hau Ng, Y.; Sik Ok, Y. Recent advances in photodegradation of antibiotic residues in water. Chem. Eng. J. 2021, 405, 126806.

6. Cao, X.; Xiao, F.; Lyu, Z.; Xie, X.; Zhang, Z.; Dong, X.; Wang, J.; Lyu, X.; Zhang, Y.; Liang, Y. CuFe2O4 supported on montmorillonite to activate peroxymonosulfate for efficient ofloxacin degradation. J. Water Process Eng. 2021, 44, 102359.

7. Wammer, K.H.; Korte, A.R.; Lundeen, R.A.; Sundberg, J.E.; McNeill, K.; Arnold, W.A. Direct photochemistry of three fluoroquinolone antibacterials: Norfloxacin, ofloxacin, and enrofloxacin. Water Res. 2013, 47, 439-448.

8. Xu, P.; Zheng, D.; He, Q.; Yu, J. The feasibility of ofloxacin degradation and electricity generation in photo-assisted microbial fuel cells with LiNbO3/CF photocatalytic cathode. Sep. Purif. Technol. 2020, 250, 117106.

9. Liu, X.; Liu, Y.; Lu, S.; Wang, Z.; Wang, Y.; Zhang, G.; Guo, X.; Guo, W.; Zhang, T.; Xi, B. Degradation difference of ofloxacin and levofloxacin by UV/H2O2 and UV/PS (persulfate): Efficiency, factors and mechanism. Chem. Eng. J. 2020, 385, 123987.

10. Zhu, Y.; Wei, M.; Pan, Z.; Li, L.; Liang, J.; Yu, K.; Zhang, Y. Ultraviolet/peroxydisulfate degradation of ofloxacin in seawater: Kinetics, mechanism and toxicity of products. Sci. Total Environ. 2020, 705, 135960.

11. Liu, B.; Li, Y.; Wu, Y.; Xing, S. Enhanced degradation of ofloxacin by persulfate activation with Mn doped CuO: Synergetic effect between adsorption and non-radical activation. Chem. Eng. J. 2021, 417, 127972.

12. Squad. S.T Rate Law - Definition, Equation and Examples I Science Terms Available online: https://scienceterms.net/chemistry/rate-law/ (accessed on Nov 23, 2021).

13. Batakliev, T.; Georgiev, V.; Anachkov, M.; Rakovsky, S.; Zaikov, G.E. Ozone decomposition. Phys. Chem. Res. Eng. Appl. Sci. Vol. 1 Princ. Technol. Implic. 2015, 7, 273-304.

14. Bagshaw, C.R. Order of Reaction. In Encyclopedia of Biophysics; Roberts, G.C.K., Ed.; Springer Berlin Heidelberg: Berlin, Heidelberg, 2013; pp. 1807-1808 ISBN 978-3-642-16712-6.

15. Rendel, P.M.; Rytwo, G. The Effect of Electrolytes on the Photodegradation Kinetics of Caffeine. Catalysts 2020, 10, 644.

16. White, D.P. Chapter 14- Chemical Kinetics Available online: my.ilstu.edu/ ccmclau/che141/materials/outlines/chapter14.ppt.

17. Atkins, P.; de Paula, J. Physical Chemistry; W.H.Freemand and Co.: New York, 2006; Vol. 8th; ISBN 0-7167-8759-8.

18. IUPAC Compendium of Chemical Terminology: Gold Book. IUPAC Compend. Chem. Terminol. $2014,1670$.

19. Rytwo, G.; Klein, T.; Margalit, S.; Mor, O.; Naftali, A.; Daskal, G. A continuous-flow device for photocatalytic degradation and full mineralization of priority pollutants in water. Desalin. Water Treat. 2016, 57, 16424-16434.

20. Bouyarmane, H.; El Bekkali, C.; Labrag, J.; Es-saidi, I.; Bouhnik, O.; Abdelmoumen, H.; Laghzizil, A.; Nunzi, J.-M.; Robert, D. Photocatalytic degradation of emerging antibiotic pollutants in waters by TiO2/Hydroxyapatite nanocomposite materials. Surfaces and Interfaces 2021, 24, 101155.

21. Rytwo, G.; Levy, S.; Shahar, Y.; Lotan, I.; Zelkind, A.L.; Klein, T.; Barak, C. Health protection using clay minerals : a case study based on the removal of BPA and BPS from water. Clays Clay Miner. 2022, in press. 
23. Mishra, D.K.; Dolan, K.D.; Yang, L. Bootstrap confidence intervals for the kinetic parameters of degradation of anthocyanins in grape pomace. J. Food Process Eng. 2011, 34, 1220-1233.

24. Al-Mamun, M.R.; Kader, S.; Islam, M.S.; Khan, M.Z.H. Photocatalytic activity improvement and application of UV-TiO2 photocatalysis in textile wastewater treatment: A review. J. Environ. Chem. Eng. 2019, 7, 103248.

25. Michael, I.; Hapeshi, E.; Aceña, J.; Perez, S.; Petrović, M.; Zapata, A.; Barceló, D.; Malato, S.; Fatta-Kassinos, D. Light-induced catalytic transformation of ofloxacin by solar Fenton in various water matrices at a pilot plant: Mineralization and characterization of major intermediate products. Sci. Total Environ. 2013, 461-462, 39-48.

26. Chong, M.N.; Jin, B.; Chow, C.W.K.; Saint, C. Recent developments in photocatalytic water treatment technology: A review. Water Res. 2010, 44, 2997-3027.

27. Rendel, P.; Rytwo, G. Degradation kinetics of caffeine in water by UV/H2O2 and UV/TiO2. Desalin. Water Treat. 2020, 173, 231-242.

28. Rytwo, G.; Klein, T.; Margalit, S.; Mor, O.; Naftaly, A.; Daskal, G. A continuous-flow device for photocatalytic degradation and full mineralization of priority pollutants in water. Desalin. Water Treat. 2015, 57, 16424-16434. 